\title{
Biocontrol of powdery mildew of grapes using culture filtrate and biomass of fungal isolates
}

\section{Singh PN${ }^{1}$, Singh SK${ }^{1}$, Tetali $S^{2}{ }^{2}$ and Lagashetti $\mathrm{AC}^{1}$}

\author{
${ }^{1}$ National Fungal Culture Collection of India (NFCCI), Biodiversity and Palaeobiology Group, MACS' Agharkar \\ Research Institute, G.G. Agarkar Road, Pune, 411004, India. \\ ${ }^{2}$ Genetics and Plant Breeding group, MACS' Agharkar Research Institute, G.G. Agarkar Road, Pune, 411004, India.
}

Singh PN, Singh SK, Tetali SP, Lagashetti AC 2017 - Biocontrol of powdery mildew of grapes using culture filtrate and biomass of fungal isolates. Plant Pathology \& Quarantine 7(2), 181-189, Doi $10.5943 / \mathrm{ppq} / 7 / 2 / 12$

\begin{abstract}
Grapevine (Vitis spp.) is an important cash crop in India and powdery mildew is a common disease which causes severe loss in yield and quality of grapes. The disease is caused by the fungus Erysiphe necator (family Erysiphaceae). Cell-free culture filtrate and biomass of selected fungal isolates (Ampelomyces quisqualis, Trichoderma harzianum and Saccharomyces cerevisiae) were found to be effective for the prevention and control of powdery mildew of grape. The results of this study suggest that the tested fungal isolates have potential to be used as an alternative to chemical fungicides for the control of grape powdery mildew.
\end{abstract}

Key words - bio-control agents - disease severity - grapes - powdery mildew

\section{Introduction}

The grapevine (Vitis spp.) is one of the worlds most planted horticultural crop cultivated all over the world. The origin of cultivation of the grape (V. vinifera) is southern Caucasia, now occupied by north-west Turkey, northern Iraq, Azerbaijan and Georgia (Mullins et al. 1992). The grape itself is used for a myriad of products, ranging from fresh fruit, preserves, juice, wine and raisins. Grape is the one of the major cash crops in India. However, there are several diseases which attack grape and cause severe loss in yield as well as to the economy.

Powdery mildew (Erysiphe necator Schwein.) is one of the major destructive diseases of grapes in India. The disease affects most parts of the grape (leaves, fruits, flowers and canes). It causes curling and senescence of leaves, weakening of stems, inhibition of bud sprouting and cracking of berries, which results in large economic loss. The currently available control methods include the use of chemical fungicides, but the repeated and heavy dose application of chemical fungicides results in development of pathogen resistance, environmental contamination and also adverse effects on human, plants and other beneficial organisms (Thomas 1986, Manandhar et al. 1988). The best alternative strategy for chemical control includes the use of eco-friendly biocontrol agents to reduce the disease severity caused by powdery mildew. Many foliar diseases were successfully controlled by a number of researchers using bio-control agents under greenhouses and 
field trials (Singh et al. 2000, Abd El-Moneim 2001, Mosa 2002, El-Gamal 2003, Kamel 2003, Saber et al. 2003, McGrath 2004, Hussein et al. 2007, Ramanujam et al. 2010, Sawant 2014).

The present study was planned to test the potential of cell-free culture filtrates and biomass of the isolated fungal cultures of Ampelomyces quisqualis, Trichoderma harzianum and Saccharomyces cerevisiae to prevent and to control or cure powdery mildew disease of grape plants in an open field. Healthy seedlings of grapes were used for testing preventive measure of cell-free culture filtrate and biomass of fungal isolates. For testing curative measure, seedlings were subjected to natural infection in an open field and these diseased seedlings were used for the experiment.

\section{Materials \& Methods}

\section{Microbial isolates}

Ampelomyces quisqualis (NFCCI 222), Trichoderma harzianum (NFCCI 4090) and Saccharomyces cerevisiae (NFCCI 4094) were microbial isolates used in this study. These fungi were previously isolated from specimens collected from Pune (in 2006) and ARI Hol farm, Baramati, Maharashtra (in 2016), and identified. The cultures are deposited and accessioned in National Fungal Culture Collection of India (WDCM-932), MACS' Agharkar Research Institute, Pune, Maharashtra, India.

\section{Protocol followed for culture filtrates preparation}

Culture filtrates of the three fungi were obtained by growing the isolates on potato dextrose broth for 15 days at $20-25^{\circ} \mathrm{C}$ and centrifuged at $10,000 \mathrm{rpm}$ for $20 \mathrm{~min}$. The supernatant was filtered by passing through sterile mixed esters of cellulose acetate filter $(0.2 \mu \mathrm{m})$ (Elkot \& Derbalah 2011).

\section{Control of the powdery mildew disease on grape plants under open field condition}

The study was carried out at ARI (in open condition). Forty potted healthy seedlings of susceptible variety of grape (Thompson seedless) were used for the experiment. Two strategies, preventive and curative measures, were followed. The preventive measure experiment was started with healthy seedlings in September, just few weeks before the powdery mildew incidence commences. In preventive measure, the healthy seedlings were sprayed with cell-free culture filtrates and pelleted crushed biomass of the fungal isolates thrice with 10 days of interval between successive application before the natural emergence of disease on seedlings and then they were placed in the open field till the end of the powdery mildew season for recording observations. In the second part of the experiment the healthy seedlings were kept in an open field for the development of powdery mildew disease under natural conditions (temperature $25-28^{\circ} \mathrm{C}$, relative humidity 60 $70 \%$ approx.). The experiment started after the development of powdery mildew infection naturally on potted seedlings kept in an open field. In this curative measure, all naturally infected seedlings were selected and these seedlings ( 3 seedlings for each treatment) were sprayed with the cell-free culture filtrate and crushed biomass. While the control plants were sprayed with sterile water (Elkot $\&$ Derbalah 2011). To assess the disease, we selected three leaves for each plant (9 leaves for each treatment). The disease severity was calculated before and after treatment of each isolate.

\section{Scanning electron microscopy}

To study the effect of fungal isolates on powdery mildew of grapes, treated and untreated leaf samples were processed for scanning electron microscopy (SEM). The leaf samples were fixed with $2 \%$ glutaraldehyde for 2 hours, post fixed in $2 \%$ osmium tetroxide in $0.1 \mathrm{M}$ potassium phosphate for 12-48 hours. Specimens were dried in desiccator with silica gel for 24-48 hours (Gupta et al. 2013). The dried samples were mounted on aluminium stubs with a double stick carbon tape and coated with gold in sputter coater. A ZEISS EVO MA 15 scanning electron microscope at 20KV was used to examine the samples. 


\section{Disease severity}

Disease severity is the percentage of relevant host tissues or organ covered by symptom or lesion or damaged by the disease. Assessment of disease severity was carried out before treatment of the first inoculation (initial disease severity) and three times later with ten day's intervals. The powdery mildew disease severity was estimated by counting percentage of leaf area covered by visible powdery mildew colonies/lesions per leaf (Wang et al. 1995). For the assessment of disease severity, we examined three old leaves per plant for three plants in each treatment (i.e.9 leaves/treatment). On the basis of estimated percentage of lesions on the leaf surface: $0,0.1-5.0$, 5.1-15.0, 15.1-30.0, 30.1-45.0, 45.1-65.0, 65.1-85.0, and >85.0, each leaf was graded as: $0,1,2$, $3,4,5,6$, and 7 , respectively. Then by using the results of grading, disease severity was calculated as follows:

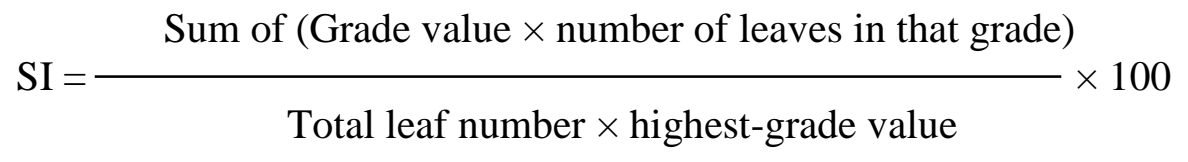

Then corrected disease severity was calculated using method described by Kamel (2003) as follows:

$$
\text { Corrected disease severity }=\mathrm{L} / \mathrm{M} \times \mathrm{N}
$$

where:

$\mathrm{L}$ - initial disease severity of treatment

$\mathrm{M}$ - initial disease severity of the control

$\mathrm{N}$ - final disease severity of the control

The presence of powdery mildew colonies on grape leaves before treatment caused wide variation in the initial disease severity under field conditions. Therefore, to assess the real comparable efficacy of treatments it was important to calculate the percent disease inhibition (DI $\%)$. The formula used for CDI \% is as follows:

$$
\mathrm{CDI} \%=\mathrm{A}-\mathrm{B} / \mathrm{A} \times 100
$$

where:

CDI - corrected disease inhibition

A - corrected final disease severity of treatment

$\mathrm{B}$ - final disease severity of treatment

\section{Results}

\section{Visual observations}

\section{Effects of culture filtrate and biomass of fungal isolates before the emergence of powdery mildew on grape plants}

It was observed that the leaves of the healthy seedlings, which were applied with culture filtrate and crushed biomass of fungal isolates, did not show the development of powdery mildew colonies even after 30 days of treatment. However, the untreated leaves (control) showed development of powdery mildew colonies (Fig 1). This clearly indicates that the cell free culture filtrate and crushed biomass of the tested microbial isolates successfully prevented or postponed the emergence of powdery mildew infection. 


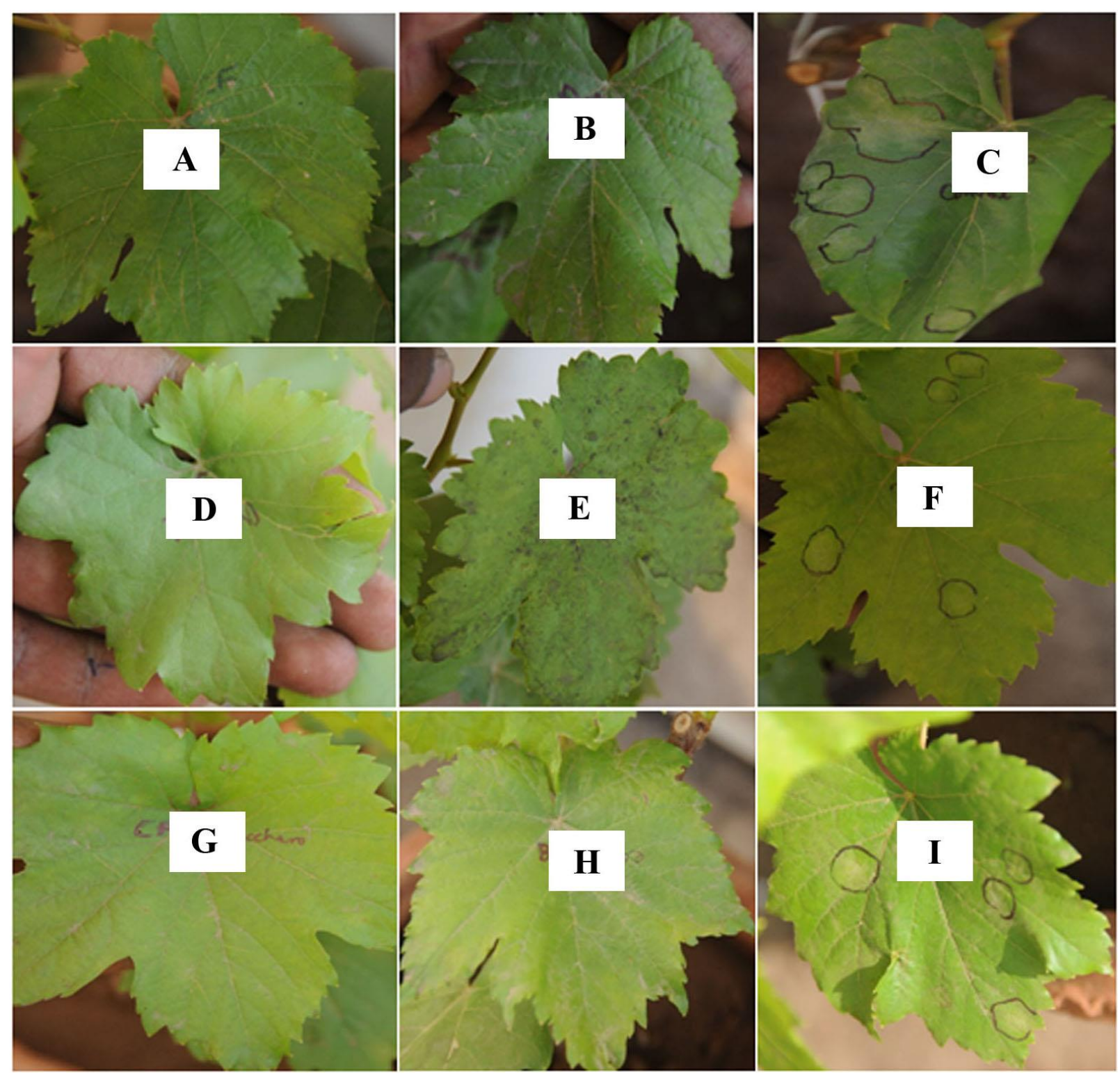

Fig 1 - Use of bioagents before emergence of disease on grape (preventive measure). A. Grape leaf treated with Ampelomyces quisqualis cell-free culture filtrate showing no development of powdery mildew, B. Grape leaf treated with A. quisqualis biomass showing no development of powdery mildew, C, F, I. Control leaves showing development of powdery mildew, D. Grape leaf treated with Trichoderma harzianum cell-free culture filtrate showing no development of powdery mildew, E. Grape leaf treated with T. harzianum biomass filtrate showing no development of powdery mildew, G. Grape leaf treated with Saccharomyces cerevisiae culture filtrate showing no development of powdery mildew, $\mathrm{H}$. Treated with $S$. cerevisiae biomass filtrate showing no development of powdery mildew.

\section{Effect of culture filtrate and biomass of fungal isolates after emergence of powdery mildew on grape plants}

The application of culture filtrates and biomass of microbial isolates significantly reduced the powdery mildew disease severity in grapes as compared to control treatment (Fig 2). The cell free culture filtrate of $T$. harzianum gave higher effectiveness against the powdery mildew on grape as compared to other two test organisms. Treatment with $T$. harzianum gave about $85-90 \%$ disease inhibition of powdery mildew on grape. T. harzianum was followed by A. quisqualis cell free culture filtrate showing about $80-85 \%$ disease inhibition, followed by $S$. cerevisiae biomass giving about $70-75 \%$ disease inhibition (Table 1 ). 

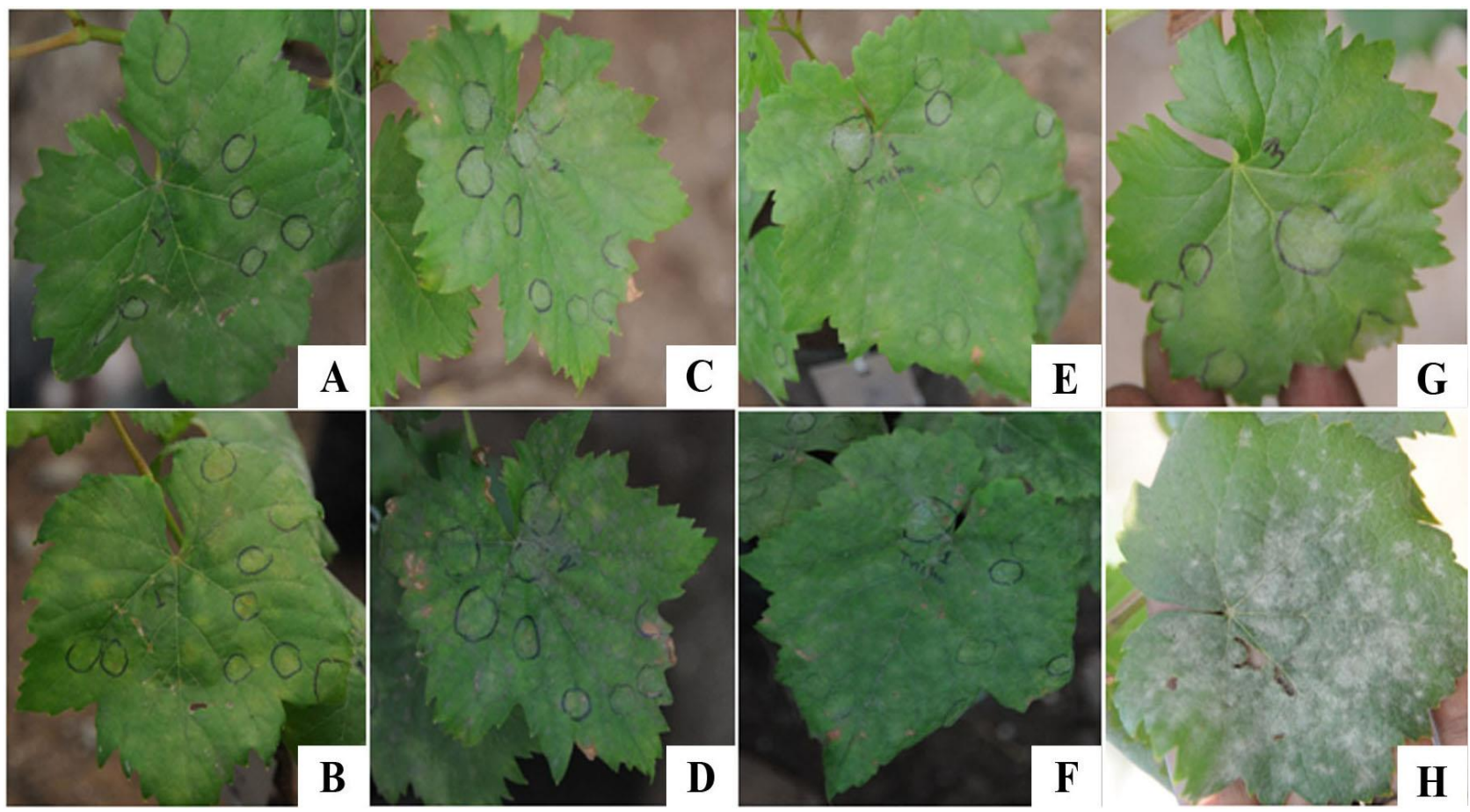

Fig 2 - Use of bioagents after disease emergence on grape (curative measure). A. A diseased grape leaf before treatment, B. Grape leaf after treatment with Ampelomyces quisqualis culture filtrate showing reduction of powdery mildew, C. A diseased grape leaf before treatment, D. Grape leaf after treatment with Saccharomyces cerevisiae biomass showing disappearance of powdery mildew, E. A diseased grape leaf before treatment, F. Grape leaf after treatment with Trichoderma harzianum culture filtrate showing disappearance of powdery mildew, G. Control leaf before treatment, H. Control leaf after treatment with sterile distilled water showing heavy infection on leaf.

Table 1 Effect of culture filtrates and biomass of fungal isolates on disease severity of powdery mildew on grape in greenhouse condition.

\begin{tabular}{|c|c|c|c|}
\hline \multirow[b]{2}{*}{ Treatment } & \multicolumn{2}{|c|}{ Disease severity (SI) \% } & \multirow{2}{*}{$\begin{array}{l}\text { Disease inhibition } \\
\% \\
\text { (corrected) }\end{array}$} \\
\hline & $\begin{array}{l}\text { Before } \\
\text { application }\end{array}$ & $\begin{array}{l}30 \text { days after start of } \\
\text { application }\end{array}$ & \\
\hline Culture filtrate of A. quisqualis & 33.33 & 3.17 & 80.42 \\
\hline Culture filtrate of $T$. harzianum & 34.92 & 1.59 & 86.41 \\
\hline Biomass of $S$. cerevisiae & 30.16 & 3.17 & 72.03 \\
\hline Control (sterile water) & 3.16 & 76.19 & 0.00 \\
\hline
\end{tabular}

\section{Microscopic examination}

Microscopic examination (SEM) of the control leaves showed that hyphae, conidiophores and conidia of the powdery mildew fungus were present in their normal condition. However, morphological abnormalities such as rupturing of hyphae and conidiophores, shrinkage, twisting, hydrolysis and decomposition of conidia of the powdery mildew fungus were observed on grape leaves treated with cell-free culture filtrate and crushed biomass of the tested microbial isolates (Fig $3)$. 

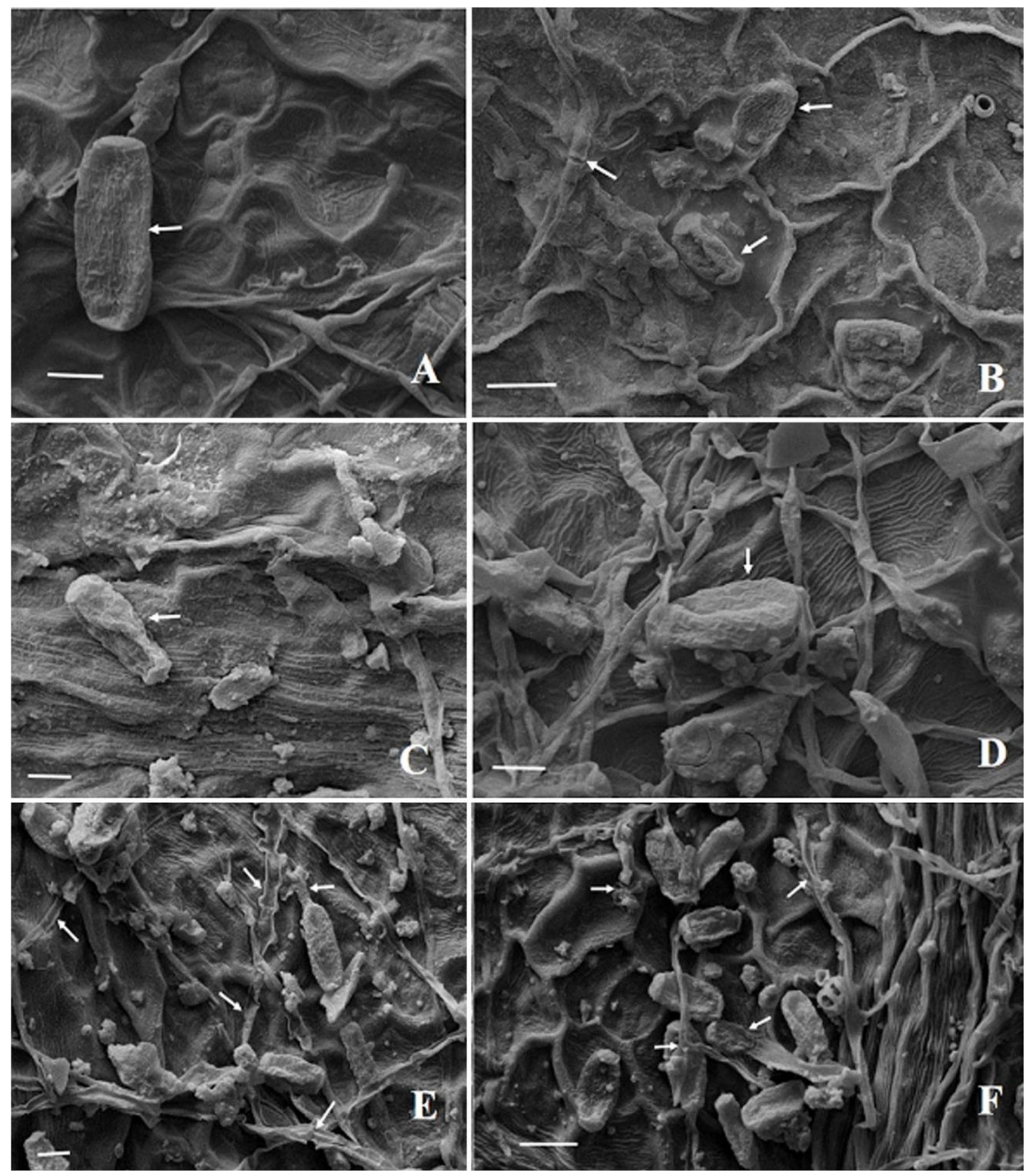

Fig 3 - Scanning electron micrographs. A. Control leaf showing normal conidia, B. Treated leaf showing cracking of hyphae and shrinkage of conidia, C. Treated leaf showing shrinkage of conidia, D. Treated leaf showing shrinkage and twisting of conidia, E. Treated leaf showing hydrolysis and decomposition of conidia and hyphae, F. Treated leaf showing shrinkage and decomposition of conidia. Scale bars $-\mathrm{A}, \mathrm{C}, \mathrm{D}, \mathrm{E}=10 \mu \mathrm{m}, \mathrm{B}, \mathrm{F}=20 \mu \mathrm{m}$.

\section{Discussion}

Nowadays biological control is considered a good alternative for prevention and suppression of powdery mildew in some crops. The myco-bioagents have ability to inhibit the growth and spread of grape powdery mildew. Many attempts have been made to use myco-bioagents against powdery mildews. Malathrakis (1985) reported the fungus Acremonium alternatum as a hyperparasite of the cucurbit powdery mildew pathogen Sphaerotheca fuliginea. The effectivity of 
Tilletiopsis albescens has been tested for the biocontrol of powdery mildew (Knudsen et al. 1993). Biocontrol of cucumber powdery mildew using phialoconidia of Verticillium lecanii has been reported by Verhaar \& Hijwegen (1993). Falk et al. (1995) reported that partial control of grape powdery mildew is possible by the use of the mycoparasite Ampelomyces quisqualis. Antibiotic producing fungi antagonistic to Erysiphe graminis have been reported for the biocontrol of powdery mildew (Lee et al. 1995). Phoma glomerata can colonize and suppress development of powdery mildew on oak and may have utility as a mycoparasitic agent (Sullivan \& White 2000). Penicillium oxalicum was found to be most effective in controlling powdery mildew in open-field nurseries of strawberries (De Cal et al. 2008), while Hegazi et al. (2010) and Elkot \& Derbalah (2011) used cultural filtrates of Epicoccum and Trichoderma species to control powdery mildew on Zinnia and squash, respectively. Biological control of powdery mildew has also been carried out by using culture filtrates of Trichoderma harzianum (Sawant 2014). The epiphytic fungus Psuedozyma aphidis was found to be effective for the biological control of cucurbit powdery mildew (Gafni et al. 2015). Recently, biological control of powdery mildew using yeast has been reported (Raghuwanshi et al. 2016).

The present preliminary study was intended to control/partially control of powdery mildew disease of grapes and to demonstrate the possibility of reducing the excessive use of chemicals in agriculture. Cell-free culture filtrates and crushed biomass of all tested fungal isolates $(A$. quisqualis, T. harzianum, S. cerevisiae) showed effectiveness against powdery mildew pathogen and significantly reduced disease severity of powdery mildew of grapes. This may be due to the production of some antifungal substances by these tested fungal isolates.

The data obtained from this study showed that cell-free culture filtrate and biomass of the tested fungal isolates successfully prevented the emergence of powdery mildew of grape plants or postponed powdery mildew emergence as there was no development of powdery mildew colonies on grape leaves even after 30 days of treatment; whereas the untreated leaves (control) showed the emergence of powdery mildew colonies.

From the visual and microscopic observations of this study it was also found that the cell-free culture filtrate and biomass of the tested fungal isolates satisfactorily control powdery mildew disease and significantly reduced the severity of powdery mildew of grapes. T. harzianum was found to be most effective against powdery mildew followed by A. quisqualis and S. cerevisieae. These preliminary results suggest that all the above tested fungal isolates can be used as a potential bioagents against grape powdery mildew.

The overall study of these experiments proves that the cell free culture filtrates and crushed biomass of the tested fungal isolates could be successfully used as bioagent against powdery mildew of grapes as a good alternative to hazardous chemical fungicides. These myco-bioagents may successfully prevent, postpone or control powdery mildew of grapes and reduce the use of chemical fungicides and minimize environmental pollution. However, the preliminary observations of bio-control potential of selected fungi, recorded in the present paper, may further require to be tested in 1-2 consecutive seasons of powdery mildew in order to validate the results. Besides, effect of tested fungi on non-target hosts is required to be tested for applying to the larger areas.

\section{Acknowledgements}

We thank Director, MACS' Agharkar Research Institute, Pune for providing facilities to carry out the research work.

\section{References}

Abd El-Moneim, Maisa L. 2001 - Evaluation of some non-chemical methods to control some soil borne fungi and foliage diseases of cucumber. Ph.D. Thesis, Faculty of Agriculture, Zagazig University, Egypt. 143 pp. 
De Cal A, Redondo C, Sztejnberg A, Melgarejo P. 2008 - Biocontrol of powdery mildew by Penicillium oxalicum in open-field nurseries of strawberries. Biological Control 47(1), $103-$ 107.

El-Gamal, Nadia G. 2003 - Usage of some biotic and abiotic agents for induction of resistance to cucumber powdery mildew under plastic house conditions. Egyptian Journal of Phytopathology 31(1-2), 129-140.

Elkot G, Derbalah A. 2011 - Use of cultural filtrates of certain microbial isolates for powdery mildew control in squash. Journal of Plant Protection Research 51(3), 252-260.

Falk SP, Gadouri DM, Pearson RC, Seem RC. 1995 - Partial control of grape powdery mildew by the mycoparasite Ampelomyces quisqualis. Plant Disease 79, 483-490.

Gafni A, Calderon C, Harris R, Buxdorf K, Dafa-Berger A, Zeilinger-Reichert E, Levy M. 2015 Biological control of the cucurbit powdery mildew pathogen Podosphaera xanthii by means of the epiphytic fungus Pseudozyma aphidis and parasitism as a mode of action. Frontiers in Plant Science 6 (132).

Gupta VK, Tuohy MG, Ayyachamy M, Turner KM, O’Donovan A. (Eds.). 2013 - Fixation of fungal structures with osmium tetroxide vapour. Fungal Biology - Current methods in fungal biology, Springer, New York. 604 pp.

Hegazi M, El-Kot G. 2010 - Biological control of powdery mildew on Zinnia (Zinnia elegans L.) using some biocontrol agents and plant extracts. Journal of Agricultural Science 2(4), 221230.

Hussein MAM, Hassan MHA, Allam ADA, Abo-El-Yous KAM. 2007 - Management of Stemphylium blight of onion by using biological agents and resistance inducers. Egyptian Journal of Phytopathology 35(1), 49-60.

Kamel SMH. 2003 - Antagonistic effects of some microbial inhibitants on phylloplane of squash plants toward Sphaerotheca fuliginea. MSc. thesis, Faculty of Agriculture Tanta University, $94 \mathrm{pp}$.

Knudsen MB, Inge, Skou JP. 1993 - The effectivity of Tilletiopsis albescens in biocontrol of powdery mildew. Annals of Applied Biology 123(1), 173-185.

Lee Yong SE, Wolf G. 1995 - Biological control of powdery mildew by antibiotic-producing microorganisms antagonistic to Erysiphe graminis. Journal of Microbiology and Biotechnology 5(6), 341-345.

Malathrakis NE. 1985 - The fungus Acremonium alternatum Line: Fr., a hyperparasite of the cucurbits powdery mildew pathogen Sphaerotheca fuliginea. Plant Diseases and Protection 92(5), 509-515.

Manandhar JB, Hartman GL, Sinclair JB. 1988 - Soybean germplasm evaluation for resistance to Colletotricum truncatum. Plant Disease 72, 56-59.

McGrath MT. 2004 - Protectant fungicides for managing powdery mildew in cucurbits: how do they stack up? Vegetable MD On line. Department of Plant Pathology, Ithaca, NY 14833. Magaret Tuttle McGrath, Associate Professor, Department of Plant Pathology, Long Island Horticulture Research and Extension Center / Cornell University 3059 Sound Avenue, River heals NY1190, May Zaeir.

Mosa AA. 2002 - Induced resistance in rice against blast disease using a biotic and biotic agent. Annals of Agricultural Sciences, Ain Shams University, Cairo 47(3), 993-1008.

Mullins MG, Bouquet A, Williams LE. (Eds). 1992 - Biology of the Grapevine. Cambridge University Press, Cambridge. 239 pp.

Raghuwanshi KS, Tekale MV. 2016 - Biological management of powdery mildew of grape. In $6^{\text {th }}$ international conference "Plant, Pathogens and People" February 23-27, 2016, New Delhi, India.

Ramanujam B, Prasad RD, Sriram S, Rangeswaran R. 2010 - Mass production, formulation, quality control and delivery of Trichoderma for plant disease management. The Journal of Plant Protection Sciences 2(2), 1-8. 
Saber MM, Abdou YA, El-Gantiry SM, Ahmed SS. 2003 - Biocontrol of anthracnose disease of soybean caused by Colletotricum dematium. Egyptian Journal of Phytopathology 31(1-2), $17-29$.

Sawant IS. 2014 - Trichoderma - foliar pathogen interactions. The Open Mycology Journal 8 (Suppl-1, M3), 58-70.

Singh UP, Prithiviraj B, Singh KP, Sarma BK. 2000 - Control of powdery mildew (Erysiphe pisi) of pea (Pisum sativum) by combined application of plant growth promoting. Zeitschritplanzenkrankheiten und planzenschutz 107, 59-66.

Sullivan RF, White JF Jr. 2000 - Phoma glomerata as a mycoparasite of powdery mildew. Applied Environmental Microbiology 66(1), 425-427.

Thomas CE. 1986 - Downy and powdery mildew resistant muskmelon breeding line MR-1. Horticultural Science 21(2), 329.

Verhaar MA, Hijwegen T. 1993 - Efficient production of phialoconidia of Verticillium lecanii for biocontrol of cucumber powdery mildew, Sphaerotheca fuliginea. European Journal of Plant Pathology 99(2), 101-103.

Wang Y, Liu Y, He P, Chen J, Lamikanra O, Luz J. 1995 - Evaluation of foliar resistance to Uncinula necator in Chinese wild Vitis species. Vitis 34(3), 159-164. 